\title{
Clinical and Demographic Features of 76 Children with Autism Spectrum Disorders at a Centre in Pakistan
}

\author{
Ghazal Nadeem1, Aleena Bibi1, Bushra Suhaib1, Suhaib Ahmed1,3 and Salman Ali2
}

\begin{abstract}
In this cross-sectional study, 76 consecutive children with autism spectrum disorder (ASD) were studied for the clinical and demographic parameters at Autism Resource Centre in Pakistan. The median age at first consultation was 30 months, 36 months at diagnosis, and 42 months at referral to a specialised centre. Clinical psychologists, therapists and paediatricians were the most frequently involved people in diagnosis. There was an average delay of one year between the first consultation and referral to the specialised centre. The male to female ratio was 4.4:1. Consanguinity was observed in 33 (43.4\%) children. Three children had another affected sibling. Half of the children were from the affluent class, while two-thirds of the parents were professionals having good education. The severity of ASD showed that $13(17 \%)$ children had borderline features, $50(66 \%)$ had mild to moderate ASD, while $13(17 \%)$ had severe ASD.
\end{abstract}

Key Words: Autism spectrum disorders, Ages, Consanguinity, Socio-economic status, Severity of disease, Pakistan.

Autism spectrum disorders (ASD) are a complex neurodevelopmental disorder characterised by failure to communicate, poor social interaction, and repetitive behaviour. The symptoms of ASD usually appear in the first two to three years of life. 1 The prevalence of ASD in the US is reported to be $16.9 / 1000$ (1:59) children.2 Population-based data are not available from Pakistan; but the prevalence of ASD is not expected to be different from the rest of the world.

Like many other developing countries, autism is a neglected health issue in Pakistan and the level of awareness amongst the health professionals and the public is low. ${ }^{3}$ The children with ASD are generally lumped together with the other learning disabilities. There are only a few places in the big cities where specialised care is available. Autism Resource Centre (ARC) Rawalpindi is one such facility that is working since 2011 under the umbrella of Autism Society of Pakistan (http://autismpak.com). It is a non-profit organisation that provides services for diagnosis and management of children with ASD.

This descriptive cross-sectional study of 76 consecutive children with ASD was conducted from January 2013 to April 2018 at ARC Rawalpindi. The study was approved by the Ethical Review Committee of the ASP Board of Directors. An informed consent was obtained from the parents of the children. The children were assessed by experienced clinical psychologists using the Diagnostic

1 Autism Resource Centre, Rawalpindi, Pakistan

2 Fazaia Medical College, Air University, Islamabad, Pakistan

3 Riphah International University, Islamabad, Pakistan

Correspondence: Prof. Suhaib Ahmed, Autism Resource Centre, Rawalpindi, Pakistan

E-mail: suhaib.ahmed@riphah.edu.pk

Received: July 13, 2018; Accepted: October 03, 2018 and Statistical Manual of Mental Disorders 5th Edition (DSM-V) criteria. ${ }^{1}$

The median age at first recognition was 29 months (range 6-58 months) and mostly the parents were the first to recognise the problem $(67 \%$, Table I). The median age at first consultation was 30 months (range 6-84 months). Paediatricians and clinical psychologists were the most frequently consulted for the problem. The median age at diagnosis was 36 months (range 17-96 months); and the diagnosis was mostly made by clinical psychologists and paediatricians. The median age at referral to ARC was 42 months (18-168 months). Clinical psychologists and therapists were the most frequently involved people for referring the children to ARC. There was an average delay of one year between the first consultation and referral to ARC. The male to female ratio was $4.4: 1$ and consanguinity was observed in 33 $(43.4 \%)$ children. Three $(3.9 \%)$ children had another affected sibling with ASD; and two, out of the latter three had consanguineous parents. Nearly $50 \%$ of the children were from the affluent class and only $8 \%$ belonged to the poor socio-economic group. Two-thirds of the parents were professionals having good education. There were 33 children who had never been to a school, $11(14.5 \%)$ had gone to a special school, while $32(42.1 \%)$ had dropped out of the mainstream schools. The severity of ASD showed that $13(17.1 \%)$ children had borderline features of ASD, $50(65.8 \%)$ had mild to moderate ASD, while $13(17.1 \%)$ had severe ASD. There were $22(28.9 \%)$ children on regular antipsychotic drugs, $6(7.9 \%)$ were taking antiepileptics, $6(7.9 \%)$ were taking various other medicines and the remaining $43(56.6 \%)$ were not on any medication.

Although it is not possible to completely get rid of autism, but the symptoms of ASD can be improved to a great extent by early intervention. A large number of children 
Table I: Recognition of 76 children of autism spectrum disorders with reference to the ages and the individuals involved.

\begin{tabular}{|c|c|c|c|c|c|c|c|c|}
\hline & 1st Recognition & $\%$ & $1^{\text {st }}$ Consultation & $\%$ & Diagnosis & $\%$ & Referral to ARC & $\%$ \\
\hline Age (months) & $29(6-58)$ & & $30(6-84)$ & & $36(17-96)$ & & $42(18-168)$ & \\
\hline Self & 51 & 67.1 & & & & & 3 & 3.9 \\
\hline Peers & 3 & 3.9 & & & & & & \\
\hline GP & & & 9 & 11.8 & & & & \\
\hline Psychiatrist & & & 6 & 7.9 & 11 & 14.5 & 3 & 3.9 \\
\hline Clinical psychologist & & & 15 & 19.7 & 31 & 40.8 & 13 & 17.1 \\
\hline Paediatrician & & & 27 & 35.5 & 14 & 18.4 & 3 & 3.9 \\
\hline Therapist & & & 11 & 14.5 & 13 & 17.1 & 16 & 21.1 \\
\hline Others & 22 & 28.9 & 8 & 10.5 & 7 & 9.2 & 38 & 50.0 \\
\hline Total & 76 & 100.0 & 76 & 100.0 & 76 & 100.0 & 76 & 100.0 \\
\hline
\end{tabular}

with ASD can expect to go to a mainstream school.4 However, the therapies for autism give best results when these are started early in life. Therefore, recognition of autism at an early stage is of fundamental importance. In this study of a fairly large number of children with ASD, the median age at first recognition (29 months) is not different from that reported in the literature. ${ }^{5}$ However, an average delay of one year was noted between the diagnosis and referral of the child to ARC. The delay in early intervention can be detrimental. It can be minimised by creating awareness amongst the healthcare providers, especially the paediatricians. ${ }^{3}$ This can be achieved through mass media, educational seminars and workshops.

ASD is reported to be more frequent in the affluent class of people. 6 But it could be due to the difficulties in accessing diagnostic and therapeutic services by the children from the low-income families. In spite of a substantial fee subsidy, the representation from the lower-income group in this study remains low. Similarly, two thirds of the children were born to parents with good education and profession. A better awareness amongst the educated parents may be a significant factor in over representation by the children with educated parents. A study from Sweden with quality healthcare services also found no excess of ASD among children of high socioeconomic status. ${ }^{7}$ It appears that there may be a tendency for the educated families and those with better financial resources to seek a diagnosis of ASD. There is a need to conduct a population-based survey for making a true estimate of the children with ASD in all segments of the population. There would also be a need to develop cost-effective service delivery for the underprivileged families having children with ASD.

\section{REFERENCES}

1. American Psychiatric Association. Diagnostic and statistical manual of mental disorders. 5th ed. Arlington, VA: American Psychiatric Association Publishing 2013.

2. Baio J, Wiggins L, Christensen DL, Maenner MJ, Daniels J, Warren Z, et al. Prevalence of autism spectrum disorder among children aged 8 years - Autism and developmental disabilities monitoring network, 11 sites, United States. 2014. MMWR Surveill Summ 2018; 67:1-23.

3. Rahbar MH, Ibrahim K, Assassi P. Knowledge and attitude of general practitioners regarding autism in Karachi, Pakistan. J Autism Dev Disord 2011; 41:465-74.

4. Taha GRA, Hussein $\mathrm{H}$. Autism spectrum disorders in developing countries: Lessons from the Arab world. In: Patel V, Preedy V, Martin C, eds. Comprehensive guide to autism. Springer, New York, NY; 2014.

5. Alshaban F, Aldosari M, El Sayed Z, Tolefat M, El Hag S, Al Shammari $\mathrm{H}$, et al. Autism spectrum disorder in Qatar: Profiles and correlates of a large clinical sample. Autism Dev Lang Impair 2017; 2:1-7.

6. Durkin MS, Maenner MJ, Meaney FJ, Levy SE, Di Guiseppi C, Nicholas JS, et al. Socioeconomic inequality in the prevalence of autism spectrum disorder: evidence from a U.S. crosssectional study. PLoS One 2010; 5:e11551.

7. Rai D, Lewis G, Lundberg M, Araya R, Svensson A, Dalman C, et al. Parental socioeconomic status and risk of offspring autism spectrum disorders in a Swedish population-based study. J Am Acad Child Adolesc Psychiatry 2012; 51:467-76. 